\title{
Metabolic stability and its role in the discovery of new chemical entities
}

\author{
KAROLINA SŁOCZYŃSKA ${ }^{1, *}$ \\ AGNIESZKA GUNIA-KRZYŻAK² \\ PAULINA KOCZURKIEWICZ ${ }^{1}$ \\ KATARZYNA WÓJCIK-PSZCZOŁA ${ }^{1}$ \\ DOROTA ŻELASZCZYK ${ }^{2}$ \\ JUSTYNA POPIÓ ${ }^{2}$ \\ ELŻBIETA PĘKALA ${ }^{1}$ \\ ${ }^{1}$ Department of Pharmaceutical
Biochemistry
Faculty of Pharmacy, Jagiellonian
University Medical College
30-688 Krakow, Poland \\ ${ }^{2}$ Department of Bioorganic Chemistry \\ Chair of Organic Chemistry \\ Faculty of Pharmacy \\ Jagiellonian University Medical \\ College, 30-688 Krakow, Poland
}

Accepted December 29, 2018

Published online January 21, 2019

\begin{abstract}
Determination of metabolic profiles of new chemical entities is a key step in the process of drug discovery, since it influences pharmacokinetic characteristics of therapeutic compounds. One of the main challenges of medicinal chemistry is not only to design compounds demonstrating beneficial activity, but also molecules exhibiting favourable pharmacokinetic parameters. Chemical compounds can be divided into those which are metabolized relatively fast and those which undergo slow biotransformation. Rapid biotransformation reduces exposure to the maternal compound and may lead to the generation of active, nonactive or toxic metabolites. In contrast, high metabolic stability may promote interactions between drugs and lead to parent compound toxicity. In the present paper, issues of compound metabolic stability will be discussed, with special emphasis on its significance, in vitro metabolic stability testing, dilemmas regarding in vitro-in vivo extrapolation of the results and some aspects relating to different preclinical species used in in vitro metabolic stability assessment of compounds.
\end{abstract}

Keywords: metabolic stability, biotransformation, intrinsic clearance, in vitro half-life, metabolites, new chemical entity

\section{INTRODUCTION}

To induce systemic effects in the body, xenobiotics such as drugs must pass plasma membranes in order to bind to the appropriate receptors. Subsequently, active lipophilic compounds are transformed to more polar derivatives, which can be easily eliminated from the body.

In general, drug metabolism can be divided into phase I and phase II. Phase I enzymes are cytochrome P450 (CYP) monooxygenases and flavin containing monooxygenases (FMO), which catalyze oxidation, reduction and hydrolysis reactions. In phase II biotransformation, metabolites rendered in phase I undergo conjugation reactions mediated by enzymes such as UDP-glucuronyl transferases or sulfotransferases (1-5). Determination of metabolic

\footnotetext{
*Correspondence, e-mail: karolina.sloczynska@uj.edu.pl
} 
stability and fate of a new chemical entity (NCE) is a crucial step in the early phases of the drug discovery and development process, since it greatly influences pharmacokinetic characteristics of therapeutic compounds (6-8). Key issues in this field are drug metabolic stability and drug metabolic profile evaluation.

In general, therapeutic compounds can be divided into those which are metabolized relatively fast and those which undergo slow biotransformation. Rapid biotransformation usually reduces exposure to the bioactive maternal compound and may lead to the generation of active, non-active or toxic metabolites. However, too metabolically stable compounds may promote interactions between drugs and favour parent compound toxic effects.

Nowadays, one of the main challenges of medicinal chemistry and scientists is not only to design chemical compounds demonstrating beneficial activity, but also to select molecules exhibiting suitable pharmacokinetic parameters necessary to elicit a favourable duration of action (9). Therefore, metabolic stability issues of compounds will be discussed in this paper, with special emphasis on the significance of metabolic stability, overview of in vitro metabolic stability testing, dilemmas regarding in vitro-in vivo extrapolation (IVIVE) of the results and some aspects relating to different preclinical species used in NCE in vitro metabolic stability evaluation.

Thus far, several good reviews in the field have been published $(2,10-16)$. The above mentioned papers, however, were mainly focused on single issues such as in vitro metabolic stability testing development, comparison of methods for the assessment of drug metabolic stability, and prediction of in vivo metabolic parameters using data from in vitro assays.

\section{METABOLIC STABILITY AND ITS SIGNIFICANCE}

Metabolic stability refers to compound susceptibility to biotransformation. Both in vitro half-life $\left(t_{1 / 2}\right)$ and intrinsic clearance $\left(\mathrm{CL}_{\text {int }}\right)$ are utilized to express metabolic stability. $t_{1 / 2}$ is used to express the time for $50 \%$ disappearance of the parent compound, whereas $\mathrm{CL}_{\text {int }}$ describes the maximum activity of liver (microsomal proteins or hepatocytes) towards a compound not influenced by other physiological determinants such as hepatic blood flow and drug binding within the blood matrix $(2,17)$. Further, additional indices including the compound hepatic clearance $\left(\mathrm{CL}_{\mathrm{H}}\right)$, bioavailability, and in vivo half-life can be predicted with different models $(2,18-21)$.

As most therapeutic compounds are biotransformed in the liver tissue, especially $\mathrm{CL}_{\mathrm{H}}$ parameter is of great importance during drug development (16).

When NCE metabolic stability is evaluated with a liver microsomal model, microsomal intrinsic clearance $\left(\mathrm{CL}_{\text {int,micr }}\right)$ is determined. $\mathrm{CL}_{\text {int,micr }}\left(\mu \mathrm{L} \mathrm{min} \mathrm{mg}^{-1}\right)$ is then scaled to in vivo intrinsic (hepatic) clearance $\left(\mathrm{CL}_{\mathrm{int}}\right)\left(\mathrm{mL} \mathrm{min}^{-1} \mathrm{~kg}^{-1}\right)$ using suitable scaling factors [including microsomal protein content per gram of liver (MPPGL) and liver mass] obtained from the literature (Table I) $(2,19,20,22,23)$.

NCE metabolic stability can be interpreted using different approaches, since compounds can be ranked in terms of their $\mathrm{CL}_{\text {int }}$ and in vitro $t_{1 / 2}$ values or based on parent structure loss during metabolic reactions. According to Di and Obach (31), the low limit of $\mathrm{CL}_{\text {int,micr }}$ measurements is about $12 \mu \mathrm{L} \mathrm{min}{ }^{-1} \mathrm{mg}^{-1}$ protein. McNaney et al. (20) classified compounds with $\mathrm{CL}_{\text {int }}$ above $45 \mathrm{~mL} \mathrm{~min}^{-1} \mathrm{~kg}^{-1}$ as high clearance compounds, NCE with 
Table I. Metabolic stability in liver microsomes, in vitro half-life and intrinsic clearance determination

\begin{tabular}{|c|c|c|c|c|}
\hline Symbol & Description & How to calculate/establish & Unit & References \\
\hline$t_{1 / 2}$ & $\begin{array}{l}\text { In vitro } \\
\text { half-life }\end{array}$ & $\begin{array}{l}\text { Established from the slope of linear } \\
\text { regression of the percentage parent } \\
\text { compound remaining against time }\end{array}$ & $\min$ & $2,24,25$ \\
\hline $\mathrm{CL}_{\text {int,micr }}$ & $\begin{array}{l}\text { Microsomal } \\
\text { intrinsic } \\
\text { clearance }\end{array}$ & $\begin{array}{l}\text { Based on the equation: } \\
\mathrm{Cl}_{\text {int,micr }}=\ln 2 / t_{1 / 2} \times[\text { volume of incubation } \\
\text { medium }(\mu \mathrm{l}) / \text { microsomal protein in } \\
\text { incubation }(\mathrm{mg})]\end{array}$ & $\mu \mathrm{L} \min ^{-1} \mathrm{mg}^{-1}$ & $2,24-26$ \\
\hline \multirow[t]{2}{*}{$\mathrm{CL}_{\text {int }}$} & $\begin{array}{l}\text { In vivo } \\
\text { intrinsic } \\
\text { (hepatic) } \\
\text { clearance }\end{array}$ & $\begin{array}{l}\text { Estimated from liver microsomal data using } \\
\text { the equation and suitable scaling factors: } \\
\mathrm{CL}_{\text {int }}=\mathrm{CL}_{\text {int, micr }} \times\left(\text { mg microsome } \mathrm{g}^{-1} \text { liver }\right) \\
\times[\text { liver mass }(\mathrm{g}) / \text { body mass }(\mathrm{kg})]\end{array}$ & $\mathrm{mL} \min ^{-1} \mathrm{~kg}^{-1}$ & $26-30$ \\
\hline & & $\begin{array}{l}\text { Scaling factors: } \\
45 \mathrm{mg} \text { of microsomal protein per gram of } \\
\text { liver tissue (humans, mice, rats, dogs, } \\
\text { monkeys/value is applied to all species) } \\
87 \mathrm{~g}, 40 \mathrm{~g}, 30 \mathrm{~g}, 32 \mathrm{~g} \text {, and } 26 \mathrm{~g} \text { of liver tissue } \\
\text { per kilogram of body weight is used for mice, } \\
\text { rats, dogs, monkeys, and humans, resp. }\end{array}$ & & \\
\hline
\end{tabular}

$\mathrm{CL}_{\text {int }}$ values between 15 and $45 \mathrm{~mL} \mathrm{~min}^{-1} \mathrm{~kg}^{-1}$ as intermediate clearance compounds, and agents with $\mathrm{CL}_{\text {int }}$ below $15 \mathrm{~mL} \mathrm{~min}^{-1} \mathrm{~kg}^{-1}$ as low clearance compounds.

High $\mathrm{CL}_{\text {int }}$ and the corresponding low in vitro $t_{1 / 2}$ values mean that the compound is rapidly metabolized, and its bioavailability in vivo will probably be low (2). Therefore, compounds can be classified on the basis of their $t_{1 / 2}$ values; e.g., in case of human CYP3A4 supersomes, compounds with $t_{1 / 2}>30$ min were classified as long $t_{1 / 2}$ compounds (e.g., carbamazepine and antipyrine); moderate $t_{1 / 2}$ agents (e.g., ketoconazole) were characterized with $t_{1 / 2}$ in the range between 10 and $30 \mathrm{~min}$, and short $t_{1 / 2}$ compounds (e.g., loperamide and buspirone) were those with $t_{1 / 2}$ below $10 \mathrm{~min}$ (32). On the other hand, in case of the microsomal stability assay with mouse liver microsomes, the following $t_{1 / 2}$ classification was suggested: compounds with $t_{1 / 2} \geq 60 \mathrm{~min}$ were defined as being stable in MLM and those with $t_{1 / 2}<30$ min were categorized as unstable agents (33).

Moreover, the parent structure loss can be monitored during an appropriate incubation period (e.g., after $15 \mathrm{~min}$ ) and three categories of substrate depletion can be distinguished: very fast (> $80 \%)$, fast (50-80\%), moderate (20-50\%), slow (5-19\%), and very slow (<5\%) (34).

Successful drug molecules should achieve and maintain sufficient concentrations at their sites of action and should be removed slowly from the body to ensure appropriate exposure to allow its effectiveness. In this context, the biggest challenges for the pharmaceutical industry during the drug discovery and development process are high clearance values, high metabolic liability and the formation of active or toxic metabolites (35).

It is noteworthy that compounds demonstrating high clearance values are usually immediately removed from the body, which leads to short duration of their therapeutic effect. On the other hand, lower clearance compounds are characterized by reduced doses, 
Table II. Some examples of low, intermediate and high clearance drugs (assay in human liver microsomes, HLM) ${ }^{a}$

\begin{tabular}{lcc}
\hline & $\begin{array}{c}\text { Intrinsic clearance } \\
\left(\mathrm{mL} \mathrm{min} \mathrm{kg}^{-1}\right)\end{array}$ \\
\hline Low & Intermediate & High \\
\hline Quinidine -3.4 & Chlorpromazine -25.0 & Verapamil - 122.0 \\
Clozapine -4.6 & Imipramine -19.0 & Propafenone -166.0 \\
Dexamethasone -3.0 & Ketamine -27.0 & Midazolam -160.0 \\
Prednisone -2.7 & Triazolam -19.0 & \\
Diazepam -2.3 & & \\
Zolpidem -2.8 & & \\
Tenoxicam -1.7 & & \\
\hline
\end{tabular}

${ }^{a}$ Ref. 40.

enhanced exposure and prolonged half-life and are hence suitable for once-daily dosing (31, 36-39). Table II provides some examples of drugs in use characterized by low, intermediate or high clearance values.

Today, in the drug discovery process great emphasis is put upon the identification of NCEs with most favourable metabolic profiles (41-43). Therefore, in-depth analysis of the chemical structure of drug candidates and identification of molecule fragments mostly responsible for its biotransformation are conducted. Modification of these "soft spots" provides the opportunity to improve the metabolic characteristics of new chemical compounds $(12,44)$.

Favourable metabolic stability profiles of NCEs are characterized by prolonged halflife and enhanced bioavailability. Moreover, reduction in metabolic turnover rates from different species is beneficial (35).

Assessment of metabolic stability. - It is vital to conduct metabolic stability studies of NCEs during the early phases of the drug discovery process, since despite showing promising in vitro activity, some molecules failed during in vivo evaluation due to poor pharmacological and toxicological results (31).

In general, drug metabolism studies are based on in vitro cellular/sub-cellular and in vivo animal models $(14,36,37,45-48)$. Undoubtedly, studies conducted in vivo with animal models are the most valuable source of data regarding NCE absorption, distribution, metabolism and excretion (ADME). Most importantly, results obtained with in vivo assays provide a complex pharmacokinetic profile of potential drug candidates. Notwithstanding, tests conducted in living systems are time-consuming, expensive and are not suitable for huge amounts of compounds. Therefore, the most recommended strategy involves preliminary in vitro assays that ensure selection of the optimal in vivo model to be employed in further drug development stages $(35,49-51)$. 
In vitro metabolic models represent a valuable alternative to animal testing, especially when large libraries of NCEs need to be evaluated and when small quantities of investigated compounds are available. Preliminary in vitro data provide the opportunity of targeted synthesis of compounds with favourable metabolic profiles, thus leading to significant cost and time reduction $(2,7,34,48)$.

Metabolic stability testing can be performed by in vitro incubation of a compound with suitable competent metabolic models (e.g., liver microsomes, hepatocytes, cDNAexpressed CYP enzymes). Next, chromatographic analysis (e.g., HPLC-MS/MS) of the resulting incubation mixtures is performed (52-54).

Among the routinely used metabolic stability in vitro systems are microsomes and hepatocytes. Microsomes are usually used to assess the CYP-mediated phase I metabolism. Some of the most important advantages of using microsomes are accessibility, various species models, procedure simplicity, limited amount of test agents used in the study and the fact that microsmes can be stored for a long period of time. On the other hand, hepatocytes, which contain intact cell membranes and physiological concentrations of enzymes, provide the most physiologically relevant model for predicting hepatic clearance $(2,15,18,37,39,48,55-58)$. Some researchers use microsomes in conjunction with hepatocytes to obtain more comprehensive results $(7,55,59-61)$.

Metabolic stability in liver microsomes. - In microsomal stability assays, microsomes coming from different species are used (e.g., human liver microsomes, HLM; mouse liver microsomes, MLM; rat liver microsomes, RLM; monkey liver microsomes, MnLM, or dog liver microsomes, DLM) (62). When human instead of animal based tests are applied, human clinical outcomes can be assessed (16). Interestingly, stability assays with MLM are not considered an ideal model for further in vivo experiments with mice. On the other hand, MLM is a good preliminary in vitro tool that can correlate well with the results obtained in metabolic assays with $\operatorname{HLM}(63,64)$.

In general, during in vitro metabolic stability assays, compounds are incubated with liver microsomes from different species. Chromatographic techniques are then used for metabolite identification (65).

In a typical microsomal stability assay, the incubation mixture consists of a test compound (dissolved in, e.g., acetonitrile, DMSO or methanol), liver microsomes, NADPHregenerating system, and potassium phosphate buffer. In order to prevent too much nonspecific binding, protein concentrations usually do not exceed $2 \mathrm{mg} \mathrm{mL}^{-1}$. In the first step, the mixture containing microsomes, test compound and buffer is pre-incubated at $37^{\circ} \mathrm{C}$ for 15 min before addition of the NADPH-regenerating system. Then, the resulting mixture is incubated at $37^{\circ} \mathrm{C}$ for several time intervals (e.g., 15, 30 and $60 \mathrm{~min}$ ). Incubation is usually not longer than $60 \mathrm{~min}$ to provide optimal conditions for enzymatic activity. Subsequently, an internal standard is added and the samples are quenched by the addition of chemicals such as perchloric acid, ice-cold methanol or cold acetonitrile. Next, the samples are centrifuged and supernatants are analyzed using chromatography methods to determine the metabolic profile of the test compound. For control samples, the NADPH-regenerating system is replaced by phosphate buffer $(2,31,66-76)$.

Metabolic stability in hepatocytes. - In the metabolic assay, hepatocytes coming from different species can be used (e.g., human, mouse, rat and dog). Hepatocyte cultures 
represent a complex metabolic system, equipped with natural orientation for linked enzymes, intact cell membranes and all the necessary physiological co-factors $(14,15,37$, 56-59). On the other hand, one of the main concerns about using freshly isolated human hepatocytes for predicting metabolic stability is their longer-term availability and their de-differentiation in culture $(16,31,39,48,77,78)$. To solve this problem, cryopreserved hepatocytes can be used (79). Moreover, some new strategies were developed, including highly specialized systems such as HepatoPac or LiverChip. HepatoPac is a micropatterned hepatocyte-fibroblast co-culture system that can be used for continuous incubation of up to 7 days, whereas LiverChip applies to a microfluidically perfused 3D hepatocyte culture system and was found useful in making low clearance measurements $(2,31,39,48,55,80)$.

During a standard procedure, hepatocyte suspensions containing 106 cells $\mathrm{mL}^{-1}$ are prepared. After preincubation of the cell suspension $\left(10 \mathrm{~min}, 37^{\circ} \mathrm{C}, 5 \% \mathrm{CO}_{2}\right)$, the investigated compound solution (e.g., in DMSO) is added to the cells. The resulting mixture is then incubated again. Samples are taken at different time points (e.g., 15, 30, 60 and $90 \mathrm{~min}$ ), and reactions are stopped with ice-cold acetonitrile or methanol. Hepatocyte-free control incubations are prepared alongside by spiking a test compound sample into culture media and aliquots are collected at 0 and $90 \mathrm{~min}$. Supernatants are then analyzed using chromatography methods for parent drugs and their metabolites $(55,63-65,81-83)$.

Metabolic stability in recombinant expressed enzymes. - Recombinant expressed enzymes provided usually by the baculovirus or the human lymphoblastoid system are the source of specific P450 isoenzymes. Among the main advantages of using the recombinant expressed enzyme model in NCE stability testing are the simplicity of the method and the possibility of using single enzymes for the study. On the other hand, the absence of the remaining phase I and phase II enzymes can be considered as a drawback of this system $(2,15)$

In a standard assay procedure, the incubation mixture is composed of a test compound solution, recombinant P450 isoenzymes, potassium phosphate buffer and $\mathrm{MgCl}_{2}$. Firstly, the mixture is pre-incubated for $15 \mathrm{~min}$ at $37^{\circ} \mathrm{C}$. Then, $\mathrm{NADPH}$ is added to start the metabolic reaction and incubation is continued for different time points (up to $60 \mathrm{~min}$ ). The reaction is terminated by the addition of an acetonitrile containing internal standard. After centrifugation, aliquots of the samples are analyzed using LC-MS/MS to remove precipitated proteins $(77,82,84,85)$.

\section{IN VITRO-IN VIVO EXTRAPOLATION}

Prediction of human pharmacokinetic indices using in vitro data still remains a big challenge in the drug discovery and development process $(86,87)$. Rergarding the drug metabolic stability testing, IVIVE is an important tool for estimating the hepatic metabolic clearance of NCEs.

When analyzing metabolic stability data coming from different in vitro models, several important issues should be taken into consideration. First of all, both the rate of metabolism and metabolic enzymes activities observed in vitro should be close to in vivo conditions. Secondly, liver should be the major organ relating to NCE clearance and non-specific protein binding should be eliminated. Moreover, the compound concentration in the incubation mixture should be below the Michaelis-Menten constant $\left(K_{M}\right)(2,14)$. 
Microsomal and hepatocyte stability assays are the key elements in high-throughput screening (HTS) of NCEs enabling the prediction of in vivo hepatic clearance. IVIVE procedure is based on the use of suitable scaling factors in order to transform the units of in vitro measured metabolic clearance to the rate of metabolism per gram of liver. Scaling factors depend on the in vitro system used. To obtain intrinsic clearance of the whole organ, the results are further multiplied by liver mass (Table I). There are appropriate scaling factors for data obtained with particular in vitro models, such as milligram of microsomal protein per gram of liver (MPPGL) for liver microsomes, number of hepatocytes per gram of liver (hepatocellularity, HPGL) for hepatocytes, and milligram of homogenate protein per gram of liver (Hom PGGL) when liver homogenates are employed (19, 45, 81, 88-91).

Many researchers have noticed that factors can influence prediction accuracy (92). In case of human MPPGL and HPGL values, inter-individual variability exists (e.g., in case of human MPPGL - $32 \mathrm{mg} \mathrm{g}^{-1}$ vs. the most commonly used $45 \mathrm{mg} \mathrm{g}^{-1}$, in case of HPGL $-99 \times$ $10^{6}$ cells $\mathrm{g}^{-1}$ vs. the most commonly used $120 \times 10^{6}$ cells g $\left.^{-1}\right)(19,61,68)$. In their study, Zhang et al. (61) proved that the mean value of MPPGL in 128 human livers was $39.46 \mathrm{mg} \mathrm{g}^{-1}$ and that up to 19-fold individual variations existed. Therefore, scaling factors should be matched to the population used.

Another problematic point relating to IVIVE are compounds that are extensively bound to plasma proteins $(50,69,92)$. Obach $(28)$ compared in vivo hepatic clearance predicted from in vitro models and $\mathrm{CL}_{\mathrm{H}}$ values measured in vivo and stated that in some cases, the clearance values predicted from the in vitro HLM model were substantially lower than those observed in vivo. It is noteworthy that such discrepancy was related to compounds with high protein binding.

According to some authors, in vitro metabolic stability assays conducted with liver microsomes represent a limited tool in predicting in vivo hepatic clearance in humans (93). On the other hand, the cryopreserved human hepatocytes model is regarded as a universal system suitable for such prediction $(14,53)$. It was observed that when metabolic liver microsomes assays were employed, a tendency to clearance over-prediction appeared. This happened particularly in the case of compounds with low passive membrane permeability (25).

According to Chiba et al. (14), comparisons between the predicted and observed metabolic clearance in human using different datasets have indicated that the in vitro metabolic clearance obtained from both human liver microsomes and cryopreserved human hepatocytes systematically under-predicted in vivo metabolic clearance approximately 9 and 3 to 6 -fold, resp.

Some authors investigated the direct in vitro-in vivo relationship of NCEs biotransoformation. Li et al. (69) evaluated the metabolism and pharmacokinetics of 4-(3,4,5-trimethoxybenzoyl)-2-phenylthiazole (SMART-H) that inhibited the proliferation of a variety of cancer cells in vitro and demonstrated that predicted clearance based on in vitro data correlated well with in vivo clearance in three animal models used in the experiment. In another study, Mukkavilli et al. (63), who examined a compound denoted as DNDI-VL-2098, a potential oral agent for visceral leishmaniasis, showed a close relationship between in vivo clearance in animal models and in vitro microsomal intrinsic clearance.

In vitro interspecies differences of NCE metabolic stability. - During in vitro metabolic stability testing, systems based on different preclinical species are employed (i.e., human, 
mouse, rat, dog and monkey). As different model organisms are used in the experiments, interspecies variations in metabolic stability are typically observed $(9,30,38,94-98)$.

One of the most important advantages of using different in vitro animal models in NCE metabolic stability assessment is the direct interspecies comparison of metabolic turnover rates and metabolic pathways. This may aid the selection of an appropriate animal model for further in vivo studies and to identify suitable surrogate species to humans, ensuring both cost and time reduction in the future in vivo experiments (35).

Interestingly, it has been regarded natural that monkey metabolism is most similar to that of humans; cynomolgus monkeys have been widely used in pharmacokinetic or drugsafety studies for that reason (99).

With reference to some drugs in use, Singh et al. (9) examined in vitro $t_{1 / 2}$ and $\mathrm{CL}_{\text {int,micr }}$ of imipramine in human, rat, mouse and dog microsomes and observed the highest $t_{1 / 2}$ values

Table III. In vitro half-life $\left(\mathrm{t}_{1 / 2}\right)$ and intrinsic clearance $\left(\mathrm{Cl}_{\text {int }}\right)$ data on some NCEs obtained with liver microsomes from various preclinical species

\begin{tabular}{|c|c|c|c|c|c|c|c|c|c|c|c|}
\hline \multirow[b]{4}{*}{ Compound } & \multicolumn{10}{|c|}{ Species } & \\
\hline & \multirow{2}{*}{\multicolumn{2}{|c|}{$\begin{array}{c}\text { Human } \\
\text { Mean }\end{array}$}} & \multirow{2}{*}{\multicolumn{2}{|c|}{$\begin{array}{l}\text { Mouse } \\
\text { Mean }\end{array}$}} & \multirow{2}{*}{\multicolumn{2}{|c|}{$\begin{array}{c}\text { Rat } \\
\text { Mean }\end{array}$}} & \multirow{2}{*}{\multicolumn{2}{|c|}{$\begin{array}{c}\text { Monkey } \\
\text { Mean }\end{array}$}} & \multicolumn{2}{|c|}{ Dog } & \\
\hline & & & & & & & & & & an & \\
\hline & 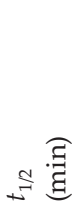 & 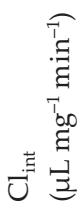 & 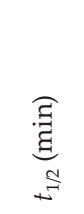 & 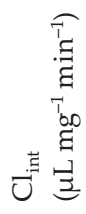 & 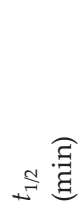 & 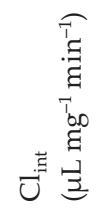 & 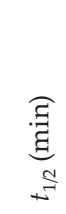 & 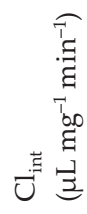 & 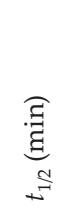 & 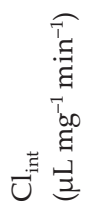 & 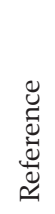 \\
\hline SB639 & 59 & - & 3 & - & 6 & - & - & - & 60 & - & 94 \\
\hline $\mathrm{I}-387$ & 24 & - & 37 & - & 42 & - & 15 & - & 29 & - & 95 \\
\hline SMART-H & 17 & - & $<<5$ & - & 31 & - & - & - & 19 & - & 69 \\
\hline KBP-7018 & - & 90 & - & 40 & - & 70 & - & 440 & - & 120 & 30 \\
\hline SCY-078 & $\geq 42$ & 34 & $\geq 125$ & $\leq 11$ & $\geq 125$ & $\leq 11$ & - & - & $\geq 29$ & $\leq 48$ & 100 \\
\hline AG-024322 & 720 & - & - & - & 18 & - & 2220 & - & 60 & - & 101 \\
\hline Orteronel $^{\circledR}$ & $>60$ & 4 & $>60$ & 3 & $>60$ & 8 & $>60$ & 3 & $>60$ & 4 & 98 \\
\hline E6201 & 36 & - & 84 & - & 89 & - & - & - & 70 & - & 96 \\
\hline FTY720-C2 & - & 18 & - & 23 & - & 80 & - & 20 & - & 6 & 97 \\
\hline FTY720-Mitoxy & - & 18 & - & 2 & - & 8 & - & 135 & - & 1 & 97 \\
\hline S002-333 & - & 27 & - & - & - & 133 & - & 137 & - & 60 & 102 \\
\hline S004-1032 & - & 25 & - & - & - & 147 & - & 70 & - & 50 & 102 \\
\hline S007-1558 & - & 36 & - & - & - & 562 & - & 318 & - & 70 & 102 \\
\hline AZ'0908 & - & 19 & - & - & - & 14 & - & - & - & 93 & 103 \\
\hline PF-02413873 & 30 & 29 & - & - & $<2$ & $>500$ & - & - & 25 & 36 & 82 \\
\hline
\end{tabular}


(and thus low $\mathrm{CL}_{\text {int,micr }}$ ) in human and dog microsomes (65 and $47 \mathrm{~min}$, resp.), whereas the lowest parameters were those in mouse and rat microsomes (11 and $5 \mathrm{~min}$, resp.).

Table III gives the in vitro half-life and intrinsic clearance data of some NCEs obtained with liver microsomes from various preclinical species.

Pelkonen et al. (7), who compared metabolic stability of 55 validation compounds [European Centre for the Validation of Alternative Methods (ECVAM)/Interagency Coordinating Committee on the Validation of Alternative Methods (ICCVAM)] using human and rat liver homogenates and microsomes, observed that as regards metabolic stability, most compounds demonstrated similar behaviour in human and rat preparations. On the other hand, Kumar et al. (96) examined in vitro microsomal stability of a novel mitogen-activated protein kinase/extracellular signal-regulated kinase, kinase-1 (MEK1) inhibitor denoted as E6201, which showed faster metabolic clearance with HLM and the highest metabolic stability with RLM.

In another study Ahn et al. (95) conducted in vitro biotransformation of a novel antimitotic agent, I-387, in HLM, MLM, RLM, DLM and MnLM. They demonstrated that the test compound was most stable in RLM with the longest $t_{1 / 2}$ and degraded rapidly in MnLM with the shortest $t_{1 / 2}$. In case of HLM, $t_{1 / 2}$ values were more similar to those of MLM and DLM than those of the other two species.

Similarly, the highest in vitro $t_{1 / 2}$ was observed in RLM by Li et al. (69), who examined the metabolism of some 4-substituted methoxybenzoyl-aryl-thiazoles with the lead compound denoted as SMART-H. In HLM and DLM, in vitro half-lives were comparable, whereas the lowest $t_{1 / 2}$ was observed in MLM. Comparable in vitro $t_{1 / 2}$ between HLM and DLM were also reported by Venkatesh et al. (94) for compound SB639, a novel histone deacetylase inhibitor. Also, Wring et al. (100) evaluated the metabolic stability of SCY-078, the first-in-class orally active antifungal glucan synthesis inhibitor, in murine models of disseminated candidiasis in microsomes coming from different species. The authors concluded that the investigated compound demonstrated low clearance with rodent microsomes and low to moderate clearance in dogs and humans. It was observed that SCY-078 was most stable in rodent microsomes and most widely metabolized in DLM. Interestingly, Zainuddin et al. (98), who investigated Orterone ${ }^{\circledR}$, a CYP17A1 enzyme inhibitor, demonstrated the highest $\mathrm{CL}_{\text {int,micr }}$ in rat microsomes, whereas the lowest values of this parameter were noticed in mouse and monkey microsomes.

Zhong et al. (101) investigated in vitro the microsomal metabolism of compound AG024322, a novel cyklin-dependent kinase (CDK) inhibitor, employing HLM, RLM, DLM and MnLM. According to their results, the test compound depleted most extensively in RLM, followed by DLM. Moreover, comparable incubations in HLM and MnLMyielded significantly less extensive parent drug depletion. On the other hand, when Huang et al. (30) investigated the in vitro microsomal stability of KBP-7018, a new tyrosine kinase inhibitor candidate for treatment of idiopathic pulmonary fibrosis, the lowest $\mathrm{CL}_{\text {int,micr }}$ was recorded in MLM and RLM, whereas the highest values were observed for MnLM.

Enoru et al. (97) assessed the preclinical metabolism of new blood-brain-barrier penetrant fingolimod analogues: FTY720-C2 and FTY720-Mitoxy. The in vitro intrinsic clearance of FTY720-C2 was low in dog, moderate in mouse, monkey and human, and high in rat, whereas in the case of the second analogue, FTY720-Mitoxy, the intrinsic clearance was found to be low in mouse, rat and dog, moderate in human and high in monkey. 
In another study, Saxena et al. (102) characterized the metabolism of S002-333 [2-(4'-methoxy-benzenesulfonyl)-2,3,4,9-tetrahydro-1H-pyrido(3,4-b)indole-3-carboxylic acid amide] and its enantiomers, S004-1032 and S007-1558, using liver microsomes from different species. In case of compound S002-333, the highest $\mathrm{CL}_{\text {int }}$ values were noted in MnLM and were comparable to the values for RLM. The lowest intrinsic clearance values were reported for HLM. In the case of enantiomers, the highest $\mathrm{CL}_{\text {int }}$ was observed for RLM, whereas the lowest were those for rabbit liver microsomes.

Bylund and Bueters (103) evaluated compound AZ'0908, a novel microsomal prostaglandin E synthase-1 inhibitor intended for oral administration. The authors found that $\mathrm{Cl}_{\text {int }}$ values in liver microsomes were significantly higher in dog than in rat and human. It is noteworthy that Bungay et al. (82), who investigated in vitro stability of PF- 02413873 (4-[3-cyclopropyl-1-(methylsulfonylmethyl)-5-methyl-1H-pyrazol-4-yl]oxy-2,6dimethylbenzonitrile), a non-steroidal progesterone receptor antagonist, observed the highest $\mathrm{Cl}_{\text {int }}$ values in RLM, whereas in DLM and HLM clearance values were significantly lower than in rat.

In summary, the above data show clearly that compounds exhibit interspecies variability in their metabolic stability, since their in vitro half-lives and intrinsic clearance values usually vary greatly when different human or animal microsomes are used. It is therefore difficult to make compound metabolic stability cross-species predictions and each model should be tested to obtain reliable data, especially in the context of further in vivo experiments. These differences in drug metabolism result from many factors, such as differences in the primary sequence and levels of CYP isoforms between various species as well as differences in their hepatic metabolism $(15,104,105)$.

\section{CONCLUSIONS}

During the drug discovery and development process, preclinical metabolic stability studies are essential to determine pharmacological and toxicological profiles of new chemical compounds. In the early phases of drug discovery, NCEs metabolic properties are determined using different in vitro systems. The obtained in vitro metabolism data are further used to predict the in vivo clearance of compounds. Moreover, preliminary in vitro experiments are useful in the selection of appropriate animal models for further in vivo studies and to identify suitable surrogate species to humans, ensuring both cost and time reduction in the future experiments. Despite the fact that in vitro-in vivo extrapolation procedures raise some questions, scientists are still working on improving this strategy to achieve more satisfactory predictions.

Acknowledgements. - This work was supported by the National Science Centre grant no. 2016/21/B/ NZ7/01756.

\section{REFERENCES}

1. S. A. Sheweita, Drug-metabolizing enzymes: mechanisms and functions, Curr. Drug Metab. 1 (2000) 107-132.

2. P. Baranczewski, A. Stańczak, K. Sundberg, R. Svensson, A. Wallin, J. Jansson, P. Garberg and H. Postlind, Introduction to in vitro estimation of metabolic stability and drug interactions of new chemical entities in drug discovery and development, Pharmacol. Rep. 58 (2006) 453-472. 
3. R. Laine, Metabolic stability: main enzymes involved and best tools to assess it, Curr. Drug Metab. 9 (2008) 921-927.

4. V. Y. Martiny and M. A. Miteva, Advances in molecular modeling of human cytochrome P450 polymorphism, J. Mol. Biol. 425 (2013) 3978-3992; https://doi.org/10.1016/j.jmb.2013.07.010

5. U. M. Zanger and M. Schwab, Cytochrome P450 enzymes in drug metabolism: regulation of gene expression, enzyme activities, and impact of genetic variation, Pharmacol. Ther. 138 (2013) 103-141; https://doi.org/10.1016/j.pharmthera.2012.12.007

6. I. Kola and C. Landis, Can the pharmaceutical industry reduce attrition rates? Nat. Rev. Drug Discov. 3 (2004) 711-715; https://doi.org/10.1038/nrd1470

7. O. Pelkonen, M. Turpeinen, J. Uusitalo, A. Rautio and H. Raunio, Prediction of drug metabolism and interactions on the basis of in vitro investigations, Basic Clin. Pharmacol. Toxicol. 96 (2005) 167-175.

8. W. A. Korfmacher, Advances in the integration of drug metabolism into the lead optimization paradigm, Mini-Rev. Med. Chem. 9 (2009) 703-716.

9. S. S. Singh, Preclinical pharmacokinetics: an approach towards safer and efficacious drugs, Curr. Drug Metab. 7 (2006) 165-182.

10. T. Iwatsubo, N. Hirota, T. Ooie, H. Suzuki, N. Shimada, K. Chiba, T. Ishizaki, C. E. Green, C. A. Tyson and Y. Sugiyama, Prediction of in vivo drug metabolism in the human liver from in vitro metabolism data, Pharmacol. Ther. 73 (1997) 147-171.

11. T. N. Thompson, Early ADME in support of drug discovery: the role of metabolic stability studies, Curr. Drug Metab. 1 (2000) 215-241.

12. C. M. Masimirembwa, U. Bredberg and T. B. Andersson, Metabolic stability for drug discovery an d development: pharmacokinetic and biochemical challenges, Clin. Pharmacokinet. 42 (2003) 515528.

13. J. B. Houston and A. Galetin, Methods for predicting in vivo pharmacokinetics using data from in vitro assays, Curr. Drug Metab. 9 (2008) 940-951.

14. M. Chiba, Y. Ishii and Y. Sugiyama, Prediction of hepatic clearance in human from in vitro data for successful drug development, AAPS J. 11 (2009) 262-276; https://doi.org/10.1208/s12248-009-9103-6

15. M. J. Gomóz-Lechón, J. V. Castell and M. T. Donato, Hepatocytes-the choice to investigate drug metabolism and toxicity in man: in vitro variability as a reflection of in vivo, Chem.-Biol. Interact. 168 (2007) 30-50.

16. D. Zhang, G. Luo, X. Ding and C. Lu, Preclinical experimental models of drug metabolism and disposition in drug discovery and development, Acta Pharm. Sin. B 2 (2012) 549-561; https://doi. org/10.1016/j.apsb.2012.10.004

17. A. P. Li, Preclinical in vitro screening assays for drug-like properties, Drug Discov. Today Technol. 2 (2005) 179-185; https://doi.org/10.1016/j.ddtec.2005.05.024

18. R. J. Riley and K. Grime, Metabolic screening in vitro: metabolic stability, CYP inhibition and induction, Drug Discov. Today Technol. 1 (2004) 365-372; https://doi.org/10.1016/j.ddtec.2004.10.008

19. Z. E. Barter, M. K. Bayliss, P. H. Beaune, A. R. Boobis, D. J. Carlile, R. J. Edwards, J. B. Houston, B. G. Lake, J. C. Lipscomb, O. R. Pelkonen, G. T. Tucker and A. Rostami-Hodjegan, Scaling factors for the extrapolation of in vivo metabolic drug clearance from in vitro data: reaching a consensus on values of human microsomal protein and hepatocellularity per gram of liver, Curr. Drug Metab. 8 (2007) 33-45.

20. C. A. McNaney, D. M. Drexler, S. Y. Hnatyshyn, T. A. Zvyaga, J. O. Knipe, J. V. Belcastro and M. Sanders, An automated liquid chromatography-mass spectrometry process to determine metabolic stability half-life and intrinsic clearance of drug candidates by substrate depletion, ASSAY Drug Dev. Technol. 6 (2008) 121-129; https://doi.org/10.1089/adt.2007.103

21. P. Chao, A. S. Uss and K. C. Cheng, Use of intrinsic clearance for prediction of human hepatic clearance, Expert Opin. Drug Metab. Toxicol. 6 (2010) 189-198; https://doi.org/10.1517/17425250903405622

22. B. Davies and T. Morris, Physiological parameters in laboratory animals and humans, Pharm. Res. 10 (1993) 1093-1095. 
23. J. B. Houston, Utility of in vitro drug metabolism data in predicting in vivo metabolic clearance, Biochem. Pharmacol. 47 (1994) 1469-1479.

24. J. K. Singh, A. Solanki and V. S. Shirsath, Comparative in vitro intrinsic clearance of imipramine in multiple species liver micrososmes: human, rat, mouse and dog, J. Drug Metab. Toxicol. 3 (2012) 126; https://doi.org/10.4172/2157-7609.1000126

25. A. Basavapathruni, E. J. Olhava, S. R. Daigle, C. A. Therkelsen, L. Jin, P. A. Boriack-Sjodin, C. J. Allain, C. R. Klaus, A. Raimondi, M. P. Scott, A. Dovletoglou, V. M. Richon, R. M. Pollock, R. A. Copeland, M. P. Moyer, R. Chesworth, P. G. Pearson and N. J. Waters, Nonclinical pharmacokinetics and metabolism of EPZ-5676, a novel DOT1L histone methyltransferase inhibitor, Biopharm. Drug Dispos. 35 (2014) 237-252; https://doi.org/10.1002/bdd.1889

26. R. S. Obach, J. G. Baxter, T. E. Liston, B. M. Silber, B. C. Jones, F. Macintyre, D. J. Rance and P. Wastall, The prediction of human pharmacokinetic parameters from preclinical and in vitro metabolism data, J. Pharmacol. Exp. Ther. 283 (1997) 46-58.

27. J. H. Lin, M. Chiba, S. K. Balani, I. W. Chen, G. Y. Kwei, K. J. Vastag and J. A. Nishime, Species differences in the pharmacokinetics and metabolism of indinavir, a potent human immunodeficiency virus protease inhibitor, Drug Metab. Dispos. 24 (1996) 1111-1120.

28. R. S. Obach, The importance of nonspecific binding in in vitro matrices, its impact on enzyme kinetic studies of drug metabolism reactions, and implications for in vitro-in vivo correlations, Drug Metab. Dispos. 24 (1996) 1047-1049.

29. F. Liu, X. Zhuang, C. Yang, Z. Li, S. Xiong, Z. Zhang, J. Li, C. Lu and Z. Zhang, Characterization of preclinical in vitro and in vivo ADME properties and prediction of human PK using a physiologically based pharmacokinetic model for YQA-14, a new dopamine D3 receptor antagonist candidate for treatment of drug addiction, Biopharm. Drug Dispos. 35 (2014) 296-307; https://doi.org/10.1002/ bdd.1897

30. Z. Huang, H. Li, Q. Zhang, X. Tan, F. Lu, H. Liu and S. Li, Characterization of preclinical in vitro and in vivo pharmacokinetics properties for KBP-7018, a new tyrosine kinase inhibitor candidate for treatment of idiopathic pulmonary fibrosis, Drug Des. Devel. Ther. 9 (2015) 4319-4328; https://doi. org/10.2147/DDDT.S83055

31. L. Di, and R. S. Obach, Addressing the challenges of low clearance in drug research, AAPS J. 17 (2015) 352-357; https://doi.org/10.1208/s12248-014-9691-7

32. P. Shah, E. Kerns, D. T. Nguyen, R. S. Obach, A. Q. Wang, A. Zakharov, J. McKew, A. Simeonov, C. E. Hop and X. Xu. An automated high-throughput metabolic stability assay using an integrated high-resolution accurate mass method and automated data analysis software, Drug Metab. Dispos. 44 (2016) 1653-1661; https://doi.org/10.1124/dmd.116.072017

33. A. L. Perryman, T. P. Stratton, S. Ekins and J. S. Freundlich. Predicting mouse liver microsomal stability with "pruned" machine learning models and public data, Pharm. Res. 33 (2016) 433-449; https://doi.org/10.1007/s11095-015-1800-5

34. O. Pelkonen, A. Telonen, T. Rousu, L. Tursas, M. Turpeinen, J. Hokkanen, J. Uusitalo, M. Bouvier $\mathrm{d}^{\prime}$ Yvoire and S. Coecke, Comparison of metabolic stability and metabolite identification of 55 ECVAM/ICCVAM validation compounds between human and rat liver homogenates and microsomes - a preliminary analysis, ALTEX 26 (2009) 214-222.

35. A. E. Nassar, A. M. Kamel and C. Clarimont, Improving the decision-making process in the structural modification of drug candidates: enhancing metabolic stability, Drug Discov. Today 9 (2004) 1020-1028.

36. E. F. Brandon, C. D. Raap, I. Meijerman, J. H. Beijnen and J. H. Schellens, An update on in vitro test methods in human hepatic drug biotransformation research: pros and cons, Toxicol. Appl. Pharmacol. 189 (2003) 233-246.

37. U. Fagerholm, Prediction of human pharmacokinetics-evaluation of methods for prediction of hepatic metabolic clearance, J. Pharm. Pharmacol. 59 (2007) 803-828. 
38. W. Richmond, M. Wogan, J. Isbell and W. P. Gordon, Interstrain differences of in vitro metabolic st ability and impact on early drug discovery, J. Pharm. Sci. 99 (2010) 4463-4468; https://doi.org/10.1002/ jps.22179

39. T. S. Chan, H. Yu, A. Moore, S. R. Khetani and D. Tweedie, Meeting the challenge of predicting hepatic clearance of compounds slowly metabolized by cytochrome P450 using a novel hepatocyte model, HepatoPac, Drug Metab. Dispos. 41 (2013) 2024-2032; https://doi.org/10.1124/dmd.113.053397

40. R. S. Obach, Prediction of human clearance of twenty-nine drugs from hepatic microsomal intrinsic clearance data: an examination of in vitro half-life approach and nonspecific binding to microsomes, Drug Metab. Dispos. 27 (1999) 1350-1359.

41. G. N. Kumar and S. Surapaneni, Role of drug metabolism in drug discovery and development, Med. Res. Rev. 21 (2001) 397-411.

42. C. M. Masimirembwa, R. Thompson and T. B. Andersson, In vitro high throughput screening of compounds for favorable metabolic properties in drug discovery, Comb. Chem. High Throughput Screen. 4 (2001) 245-263.

43. H. Zhang, D. Zhang, W. Li, M. Yao, C. D'Arienzo, Y. X. Li, W. R. Ewing, Z. Gu, Y. Zhu, N. Murugesan, W. C. Shyu and W. G. Humphreys, Reduction of site-specific CYP3A-mediated metabolism for dual angiotensin and endothelin receptor antagonists in various in vitro systems and in cynomolgus monkeys, Drug Metab. Dispos. 35 (2007) 795-805.

44. T. N. Thompson, Optimization of metabolic stability as a goal of modern drug design, Med. Res. Rev. 21 (2001) 412-449.

45. T. Iwatsubo, H. Suzuki and Y. Sugiyama, Prediction of species differences (rats, dogs, humans) in the in vivo metabolic clearance of YM796 by the liver from in vitro data, J. Pharmacol.Exp. Ther. 283 (1997) 462-469.

46. J. L. Bussiere, Species selection considerations for preclinical toxicology studies for biotherapeutics, Expert Opin. Drug Metab. Toxicol. 4 (2008) 871-877; https://doi.org/10.1517/17425255.4.7.871

47. J. A. Sahi, A comprehensive evaluation of metabolic activity and intrinsic clearance in suspensions and monolayer cultures of cryopreserved primary human hepatocytes, J. Pharm. Sci. 101 (2012) 3989-4002; https://doi.org/10.1002/jps.23262

48. L. Wang, C. W. Chiang, H. Liang, H. Wu, W. Feng, S. K. Quinney, J. Li and L. Li, How to choose in vitro systems to predict in vivo drug clearance: A system pharmacology perspective, BioMed. Res. Int. 2015 (2015) Article ID 857327 (9 pages); https://doi.org/10.1155/2015/857327

49. K. M. L. Crommentuyn, J. H. M. Schellens, J. D. Van den Berg and J. H. Beijen, In vitro metabolism of anti-cancer drugs, methods and applications: Paclitaxel, docetaxel, tamoxifen and iosfamide, Cancer Treat. Rev. 24 (1998) 345-366.

50. M. T. Donato and J. V. Castel, Strategies and molecular probes to investigate the role of cytochrome P450 in drug metabolism, Clin. Pharmacokinet. 42 (2003) 153-178.

51. N. Plant, Strategies for using in vitro screens in drug metabolism, Drug Discov. Today 9 (2004) $328-$ 336.

52. L. Jia and X. Liu, The conduct of drug metabolism studies considered good practice (II): in vitro experiments, Curr. Drug Metab. 8 (2007) 822-829.

53. P. Poulin, J. R. Kenny, C. E. Hop and S. Haddad, In vitro-in vivo extrapolation of clearance: modeling hepatic metabolic clearance of highly bound drugs and comparative assessment with existing calculation methods, J. Pharm. Sci. 101 (2012) 838-851; https://doi.org/10.1002/jps.22792.

54. S. Ma, S. K. Chowdhury and K. B. Alton, Application of mass spectrometry for metabolite identification, Curr. Drug Metab. 7 (2006) 503-523.

55. C. Lu, P. Li, R. Gallegos, V. Uttamsingh, C. Q. Xia, G. T. Miwa, S. K. Balani and L. S. Gan, Comparis on of intrinsic clearance in liver microsomes and hepatocytes from rats and humans: evaluation of free fraction and uptake in hepatocytes, Drug Metab. Dispos. 34 (2006) 1600-1605. 
56. H. S. Brown, M. Griffin and J. B. Houston, Evaluation of cryopreserved human hepatocytes as an alternative in vitro system to microsomes for the prediction of metabolic clearance, Drug Metab. Dispos. 35 (2007) 293-301.

57. J. Sahi, S. Grepper and C. Smith. Hepatocytes as a tool in drug metabolism, transport and safety evaluations in drug discovery, Curr. Drug Discov. Technol. 7 (2010) 188-198.

58. M. J. Gómez-Lechón, M. T. Donato, J. V. Castell and R. Jover, Human hepatocytes in primary culture: the choice to investigate drug metabolism in man, Curr. Drug Metab. 5 (2004) 443-462.

59. A. P. Li, In vitro human hepatocyte-based experimental systems for the evaluation of human drug metabolism, drug-drug interactions, and drug toxicity in drug development, Curr. Top. Med. Chem. 14 (2014) 1325-1338.

60. K. M. Knights, D. M. Stresser J. O. Miners and C. L. Crespi, In vitro drug metabolism using liver microsomes, Curr. Protoc. Pharmacol. 74 (2016) 7.8.1-7.8.24; https://doi.org/10.1002/cpph.9

61. H. Zhang, N. Gao, X. Tian, T. Liu, Y. Fang, J. Zhou, Q. Wen, B. Xu, B. Qi, J. Gao, H. Li, L. Jia and H. Qiao, Content and activity of human liver microsomal protein and prediction of individual hepatic clearance in vivo, Sci. Rep. 5 (2015) Article ID 17671 (12 pages); https://doi.org/10.1038/srep17671

62. P. Krüger, R. Daneshfar, G. P. Eckert, J. Klein, D. A. Volmer, U. Bahr, W. E. Müller, M. Karas, M. Schubert-Zsilavecz and M. Abdel-Tawab, Metabolism of boswellic acids in vitro and in vivo, Drug Metab. Dispos. 36 (2008) 1135-1142; https://doi.org/10.1124/dmd.107.018424

63. R. Mukkavilli, J. Pinjari, B. Patel, S. Sengottuvelan, S. Mondal, A. Gadekar, M. Verma, J. Patel, L. Pothuri, G. Chandrashekar, P. Koiram, T. Harisudhan, A. Moinuddin, D. Launay, N. Vachharajani, V. Ramanathan and D. Martin, In vitro metabolism, disposition, preclinical pharmacokinetics and prediction of human pharmacokinetics of DNDI-VL-2098, a potential oral treatment for Visceral L eishmaniasis, Eur. J. Pharm. Sci. 65 (2014) 147-155; https://doi.org/10.1016/j.ejps.2014.09.006

64. K. N. Ellefsen, A. Wohlfarth, M. J. Swortwood, X. Diao, M. Concheiro and M. A. Huestis, 4-Methoxy$\alpha$-PVP: in silico prediction, metabolic stability, and metabolite identification by human hepatocyte incubation and high-resolution mass spectrometry, Forensic Toxicol. 34 (2016) 61-75; https://doi. org/10.1007/s11419-015-0287-4

65. A. S. Gandhi, A. Wohlfarth, M. Zhu, S. Pang, M. Castaneto, K. B. Scheidweiler and M. A. Huestis, High-resolution mass spectrometric metabolite profiling of a novel synthetic designer drug, $\mathrm{N}$-(adamantan-1-yl)-(adamantan-1-yl)-1-(5-fluoropentyl)-1H-indole-3-carboxamide (STS-135), using cryopreserved human hepatocytes and assessment of metabolic stability with human liver microsomes, Drug Test. Anal. 7 (2015) 197-198; https://doi.org/10.1002/dta.1662

66. X. Zhang, J. Zhang, W. Li, L. Liu, B. Sun, Z. Guo, C. Shi and Y. Zhao, In vitro metabolism of 20(R)-25methoxyl-dammarane-3, 12, 20 triol from Panax notoginseng in human, monkey, dog, rat, and mouse liver microsomes, PLoS One 9 (2014)e94962; https://doi.org/10.1371/journal.pone.0094962

67. B. D. Palmer, A. M. Thompson, H. S. Sutherlan, A. Blaser, I. Kmentova, S. G. Franzblau, B. Wan, Y. Wang, Z. Ma and W. A. Denny, Synthesis and structure-activity studies of biphenyl analogues of the tuberculosis drug (6S)-2-nitro-6-\{[4-(trifluoromethoxy)benzyl]oxy\}-6,7-dihydro-5Himidazo[2,1-b][1,3]oxazine (PA-824), J. Med. Chem. 53 (2010) 282-294; https://doi.org/10.1021/jm901207n

68. L. Quintieri, M. Fantin, P. Palatini, S. De Martin, A. Rosato, M. Caruso, C. Geroni and M. Floreani, In vitro hepatic conversion of the anticancer agent nemorubicin to its active metabolite PNU-159682 in mice, rats and dogs: a comparison with human liver microsomes, Biochem. Pharmacol. 76 (2008) 784-795; https://doi.org/10.1016/j.bcp.2008.07.003

69. C. M. Li, Y. Lu, R. Narayanan, D. D. Miller and J. T. Dalton, Drug metabolism and pharmacokinetics of 4-substituted methoxybenzoyl-aryl-thiazoles, Drug Metab. Dispos. 38 (2010) 2032-2039; https://doi. org/10.1124/dmd.110.034348

70. L. Di, E. H. Kerns, Y. Hong, T. A. Kleintop, O. J. McConnell and D. M. Huryn, Optimization of a higher throughput microsomal stability screening assay for profiling drug discovery candidates, J. Biomol. Screen. 8 (2003) 453-462. 
71. J. Huang, L. Si, Z. Fan, L. Hu, J. Qiu and G. Li, In vitro metabolic stability and metabolite profiling of TJ0711 hydrochloride, a newly developed vasodilatory $\beta$-blocker, using a liquid chromatographytandem mass spectrometry method, J. Chromatogr. B 879 (2011) 3386-3392; https://doi/org/10.1016/j. jchromb.2011.09.010

72. C. Sakai, S. Iwano, Y. Yamazaki, A. Ando, F. Nakane, M. Kouno, H. Yamazaki and Y. Miyamoto, Species differences in the pharmacokinetic parameters of cytochrome $\mathrm{P} 450$ probe substrates between experimental animals, such as mice, rats, dogs, monkeys, and microminipigs, and humans, J. Drug Metab. Toxicol. 5 (2014) Article ID 1000173 (12 pages); https://doi.org/10.4172/2157-7609.1000173

73. K. Słoczyńska, K. Pańczyk, A. M. Waszkielewicz, H. Marona and E. Pękala, In vitro mutagenic, antimutagenic, and antioxidant activities evaluation and biotransformation of some bioactive 4-substituted 1-(2-methoxyphenyl)piperazine derivatives, J. Biochem. Mol. Toxicol. 30 (2016) 593-601; https://doi.org/10.1002/jbt.21826

74. A. Gunia-Krzyżak, D. Żelaszczyk, A. Rapacz, E. Żesławska, A. M. Waszkielewicz, K. Pańczyk, K. Słoczyńska, E. Pękala, W. Nitek, B. Filipek and H. Marona, Structure-anticonvulsant activity studies in the group of (E)-N-cinnamoyl aminoalkanols derivatives monosubstituted in phenyl ring with 4-Cl, 4- $\mathrm{CH}_{3}$ or 2- $\mathrm{CH}_{3}$, Bioorg. Med. Chem. 25 (2017) 471-482; https://doi.org/10.1016/j.bmc.2016.11.014

75. A. M. Waszkielewicz, K. Słoczyńska, E. Pękala, P. Żmudzki, A. Siwek, A. Gryboś and H. Marona, Design, synthesis, and anticonvulsant activity of some derivatives of xanthone with aminoalkanol moieties, Chem. Biol. Drug Des. 89 (2017) 339-352; https://doi.org/10.1111/cbdd.12842

76. M. Marcinkowska, M. Kołaczkowski, K. Kamiński, A. Bucki, M. Pawłowski, A. Siwek, T. Karcz, G. Starowicz, K. Słoczyńska, E. Pękala, A.Wesołowska, J. Samochowiec, P. Mierzejewski and P. Bienkowski, 3-Aminomethyl derivatives of 2-phenylimidazo[1,2-a]-pyridine as positive allosteric modulators of GABAA receptor with potential antipsychotic activity, ACS Chem. Neurosci. 8 (2017) 1291-1298; https://doi.org/10.1021/acschemneuro.6b00432

77. R. Stringer, P. L. Nicklin and J. B. Houston, Reliability of human cryopreserved hepatocytes and liver microsomes as in vitro systems to predict metabolic clearance, Xenobiotica 38 (2008) 1313-1329; https://doi.org/10.1080/00498250802446286

78. R. A. Stringer, C. Strain-Damerell, P. Nicklin and J. B. Houston, Evaluation of recombinant cytochrome p450 enzymes as an in vitro system for metabolic clearance predictions, Drug Metab. Dispos. 37 (2009) 1025-1034; https://doi.org/10.1124/dmd.108.024810

79. K. Bachmann, J. Byers and R. Ghosh, Prediction of in vivo hepatic clearance from in vitro data using cryopreserved human hepatocytes, Xenobiotica 33 (2003) 475-483.

80. U. Zanelli, N. P. Caradonna, D. Hallifax, E. Turlizzi and J. B. Houston, Comparison of cryopreserved HepaRG cells with cryopreserved human hepatocytes for prediction of clearance for 26 drugs, Drug Metab. Dispos. 40 (2016) 104-110; https://doi.org/10.1124/dmd.111.042309

81. D. F. McGinnity, M. G. Soars, R. A. Urbanowicz and R. J. Riley. Evaluation of fresh and cryopreserved hepatocytes as in vitro drug metabolism tools for the prediction of metabolic clearance, Drug Metab. Dispos. 32 (2004) 1247-1253.

82. P. J. Bungay, S. Tweedy, D. C. Howe, K. R. Gibson, H. M. Jones and N. M. Mount, Preclinical and clinical pharmacokinetics of PF-02413873, a nonsteroidal progestrone receptor antagonist, Drug Metab. Dispos. 39 (2011) 1396-1405; https://doi.org/10.1124/dmd.110.037234

83. S. Klieber, C. Arabeyre-Fabre, P. Moliner, E. Marti, M. Mandray, R. Ngo, C. Ollier, P. Brun and G. Fabre, Identification of metabolic pathways and enzyme systems involved in the in vitro human hepatic metabolism of dronedarone, a potent new oral antiarrythmic drug, Pharmacol. Res. Perspect. 2 (2014) e00044; https://doi.org/10.1002/prp2.44

84. M. D. Green, X. Yang, M. Cramer and C. D. King, In vitro metabolic studies on the selective metabotropic glutamate receptor sub-type 5 (mGluR5) antagonist 3-[(2-methyl-1,3-thiazol-4-yl) ethynyl]-pyridine (MTEP), Neurosci. Lett. 391 (2006) 91-95. 
85. A. V. Rudraraju, M. F. Hossain, A. Shrestha, P. N. A. Amoyaw, B. L. Tekwani and M. O. F. Khan, In vitro metabolic stability study of new cyclen based antimalarial drug leads using RP-HPLC and LC-MS/MS, Mod. Chem. Appl. 2 (2014) Article ID 1000129 (8 pages); https://doi.org/10.4172/23296798.1000129

86. W. Klopf and P. Worboys, Scaling in vivo pharmacokinetics from in vitro metabolic stability data in drug discovery, Comb. Chem. High Throughput Screen. 13 (2010) 159-169.

87. O. Pelkonen and H. Raunio, In vitro screening of drug metabolism during drug development: can we trust the predictions?, Expert Opin. Drug Metab. Toxicol. 1 (2005) 49-59.

88. K. Ito and J. B. Houston, Comparison of the use of liver models for predicting drug clearance using in vitro kinetic data from hepatic microsomes and isolated hepatocytes, Pharm. Res. (NY) 21 (2004) 785-792.

89. R. J. Riley, D. F. McGinnity and R. P. Austin, A unified model for predicting human hepatic, metabolic clearance from in vitro intrinsic clearance data in hepatocytes and microsomes, Drug Metab. Dispos. 33 (2005) 1304-1311.

90. B. J. Ring, J. Y. Chien, K. K. Adkison, H. M. Jones, M. Rowland, R. D. Jones, J. W. Yates, M. S. Ku, C. R. Gibson, H. He, R. Vuppugalla, P. Marathe, V. Fischer, S. Dutta, V. K. Sinha, T. Björnsson, T. Lavé and P. Poulin, PhRMA CPCDC initiative on predictive models of human pharmacokinetics; Part 3: comparative assessement of prediction methods of human clearance, J. Pharm. Sci. 100 (2011) 40904110; https://doi.org/10.1002/jps.22552

91. Z. E. Barter, G. T. Tucker and K. Rowland-Yeo, Differences in cytochrome p450-mediated pharmacokinetics between Chinese and Caucasian populations predicted by mechanistic physiologically based pharmacokinetic modelling, Clin. Pharmacokinet. 52 (2013) 1085-1100; https:// doi.org/10.1007/s40262-013-0089-y

92. H. Wan, P. Bold, L. O. Larsson, J. Ulander, S. Peters, B. Löfberg, A. L. Ungell, M. Någård and A. Llinàs, Impact of input parameters on the prediction of hepatic plasma clearance using the wellstirred model, Curr. Drug Metab. 11 (2010) 583-594; https://doi.org/10.2174/138920010792927334

93. J. C. Kalvass, D.A. Tess, C. Giragossian, M. C. Linhares, and T. S. Maurer, Influence of microsomal concentration on apparent intrinsic clearance: implications for scaling in vitro data, Drug Metab. Dispos. 29 (2001) 1332-1336.

94. P. R. Venkatesh, E. Goh, P. Zheng, L. S. New, L. Xin, M. K. Pasha, K. Sangthongpitag, P. Yeo and E. Kantharaj, In vitro phase I cytochrome P450 metabolism, permeability and pharmacokinetics of SB639, a novel histone deacetylase inhibitor in preclinical species, Biol. Pharm. Bull. 30 (2007) 10211024.

95. S. Ahn, J. D. Kearbey, C. M. Li, C. B. Duke, $3^{\text {rd }}$, D. D. Miller and J. T. Dalton, Biotransformation of a novel antimitotic agent, I-387, by mouse, rat, dog, monkey, and human liver microsomes and in vivo pharmacokinetics in mice, Drug Metab. Dispos. 39 (2011) 636-643; https://doi.org/10.1124/ dmd.110.036673

96. V. Kumar, E. L. Schuck, R. D. Pelletier, N. Farah, K. B. Condon, M. Ye, C. Rowbottom, B. M. King, Z. Y. Zhang, P. L. Saxton and Y. N. Wong, Pharmacokinetic characterization of a natural productinspired novel MEK1 inhibitor E6201 in preclinical species, Cancer Chemother. Pharmacol. 69 (2012) 229-237; https://doi.org/10.1007/s00280-011-1687-8

97. J. O. Enoru, B. Yang, S. Krishnamachari, E. Villanueva, W. DeMaio, A. Watanyar, R. Chinnasamy, J. B. Arterburn and R. G. Perez, Preclinical metabolism, pharmacokinetics and in vivo analysis of new blood-brain-barrier penetrant fingolimod analogues: FTY720-C2 and FTY720-Mitoxy, PLoS One 11 (2016) e0162162; https://doi.org/10.1371/journal.pone.0162162

98. M. Zainuddin, A. B. Vinod, S. D. Gurav, A. Police, A. Kumar, C. Mithra, P. Dewang, R. R. Kethiri and R. Mullangi, Preclinical assessment of Orteronel(®), a CYP17A1 enzyme inhibitor in rats, Eur. J. Drug Metab. Pharmacokinet. 41 (2016) 1-7; https://doi.org/10.1007/s13318-014-0229-2

99. K. Tabata, N. Hamakawa, S. Sanoh, S. Terashita and T. Teramura, Exploratory population pharmacokinetics (e-PPK) analysis for predicting human PK using exploratory ADME data during early drug discovery research, Eur. J. Drug Metab. Pharmacokinet. 34 (2009) 117-128. 
100. S. A. Wring, R. Randolph, S. Park, G. Abruzzo, Q. Chien, A. Flattery, G. Garrett, M. Peel, R. Outcalt, K. Powell, M. Truckis, D. Angulo and K. Borroto-Esoda, Preclinical pharmacokinetics and pharacodynamic target of SCY-078, a first-in-class orally active antifungal glucan synthesis inhibitor, in murine models of disseminated candidiasis, Antimicrob. Agents Chemother. 61 (2017) e02068-16 (15 pages); https://doi.org/10.1128/AAC.02068-16

101. W. Z. Zhong, B. Lalovic and J. Zhan, Characterization of in vitro and in vivo metabolism of AG024322, a novel cyclin-dependent kinase (CDK) inhibitor, Health 1 (2009) 249-262; https://doi. org/10.4236/health.2009.14041

102. A. Saxena, G. R. Valicherla, G. K. Jain, R. S. Bhatta, A. K. Saxena and J. R. Gayen, Metabolic profiling of a novel antithrombotic compound, S002-333, and its enantiomers: metabolic stability, species comparison and in vitro-in vivo extrapolation, Biopharm. Drug Dispos. 37 (2016) 185-199; https://doi.org/10.1002/bdd.1995

103. J. Bylund and T. Bueters, Presystemic metabolism of AZ'0908, a novel mPGES-1 inhibitor: an in vitro and in vivo cross-species comparison, J. Pharm. Sci. 102 (2013) 1106-1115; https://doi. org/10.1002/jps.23443

104. J. H. Lin, Applications and limitations of interspecies scaling and in vitro extrapolation in pharmacokinetics, Drug Metab. Dispos. 26 (1998) 1202-1212.

105. H. Bun, B. Disdier, C. Aubert and J. Catalin, Interspecies variability and drug interactions of clozapine metabolism by microsomes, Fundam. Clin. Pharmacol. 13 (1999) 577-581. 